\title{
A dedicated microarray for in-depth analysis of pre-mRNA splicing events: application to the study of genes involved in the response to targeted anticancer therapies
}

\author{
Marine Pesson ${ }^{1}$, Béatrice Eymin ${ }^{2}$, Pierre De La Grange ${ }^{3}$, Brigitte Simon ${ }^{1}$ and Laurent $\operatorname{Corcos}^{1 *}$
}

\begin{abstract}
Alternative pre-mRNA splicing (AS) widely expands proteome diversity through the combinatorial assembly of exons. The analysis of AS on a large scale, by using splice-sensitive microarrays, is a highly efficient method to detect the majority of known and predicted alternative transcripts for a given gene. The response to targeted anticancer therapies cannot easily be anticipated without prior knowledge of the expression, by the tumor, of target proteins or genes. To analyze, in depth, transcript structure and levels for genes involved in these responses, including AKT1-3, HER1-4, HIFIA, PIK3CA, PIK3R1-2, VEGFA-D and PIR, we engineered a dedicated gene chip with coverage of an average 185 probes per gene and, especially, exon-exon junction probes. As a proof of concept, we demonstrated the ability of such a chip to detect the effects of over-expressed SRSF2 RNA binding protein on the structure and abundance of mRNA products in H358 lung cancer cells conditionally over-expressing SRSF2. Major splicing changes were observed, including in HERT/EGFR pre-mRNA, which were also seen in human lung cancer samples over-expressing the SRSF2 protein. In addition, we showed that variations in HER1/EGFR pre-mRNA splicing triggered by SRSF2 overexpression in H358 cells resulted in a drop in HER1/EGFR protein level, which correlated with increased sensitivity to gefitinib, an EGFR tyrosine kinase inhibitor. We propose, therefore, that this novel tool could be especially relevant for clinical applications, with the aim to predict the response before treatment.
\end{abstract}

Keywords: DNA chip, Targeted anticancer therapies, Pre-mRNA splicing, SRSF2

\section{Background}

Alternative pre-mRNA splicing (AS) occurs for an estimated $90 \%$ of genes in the human genome [1], with remarkable repercussions on proteome diversity [2]. The outcome of AS strongly depends on context. Hence, AS occurs to allow the onset of development or differentiation programs, to participate in cancer occurrence or progression, and to develop integrated responses to stressful conditions [3-5]. Importantly, AS transcripts may encode alternative protein isoforms, which quite often display distinct or even opposite functions, such as for the pro- or anti-apoptotic caspases or Bcl-2 family proteins [6-8]. In addition, AS may also lead to the assembly of

\footnotetext{
* Correspondence: laurent.corcos@inserm.fr

'UMR INSERM U1078-UBO, Equipe ECLA, Faculté de Médecine, 22 Avenue Camille Desmoulins, 29200 Brest, France

Full list of author information is available at the end of the article
}

short-lived mRNAs targeted to degradation through the nonsense mediated decay (NMD) system [9]. However, even if NMD transcripts do not encode proteins, their occurrence may modify the ratio of mRNA isoforms, potentially affecting protein synthesis outcome [10].

Analytical tools to study AS on a large scale have been developed by Affymetrix ${ }^{\mathrm{m}}$, with the Human Exon 1.0 ST arrays, also referred to as splice-sensitive microarrays, which allow surveying known and predicted AS events throughout the transcriptome $[11,12]$. Recently, deep sequencing methods have made it possible to determine both mRNA levels and structure [13-15]. Nevertheless, the mathematical tools necessary to decipher the structure and amount of mRNA species identified by sequencing are still under constant development $[16,17]$. In addition, a recent comparison between RNA-Seq and Affymetrix ${ }^{\mathrm{m}}$ Exon arrays has revealed that the chip method was more 
powerful at detecting and quantifying exons [18]. It was also demonstrated that microarray technologies could be used as a reliable routine diagnostic tool, thanks to the development of a small custom-made microarray able to predict disease outcome in breast cancer patients [19]. Following on that path, the aim of the present study was to develop a customized microarray enabling to detect both known and predictable AS events for a small number of genes involved in tumor growth and in the response to targeted anticancer therapies. To take advantage of the DNA chip experimental setup, we wished to improve the methodology by increasing the amount of probes, including exon-exon junction probes absent from Affymetrix ${ }^{\text {ma }}$ Exon arrays, which would allow detecting virtually all AS events that could occur in this subset of genes.

Targeted anticancer therapies include drugs, such as inhibitors of tyrosine kinase or monoclonal antibodies (mAbs), which oppose cell growth signaling or tumor blood vessel development, promote the specific death of cancer cells, or stimulate the immune system. Among specific molecules with which targeted therapies interfere, the HER (human epidermal growth factor receptor) family regulates cell growth, survival, adhesion, migration and differentiation. Trastuzumab $\left(\right.$ Herceptin $\left.^{\mathrm{rm}}\right)$, which was FDA-approved in 2000, was the first treatment using a humanized $\mathrm{mAb}$ to target the receptor tyrosine kinase encoded by the HER2 oncogene, and is mainly used to treat breast cancers over-expressing this receptor [20,21]. Cetuximab (Erbitux ${ }^{\mathrm{mm}}$ ) and gefitinib (Iressa ${ }^{\mathrm{m}}$ ) target HER1/ EGFR (epithelial growth factor receptor), or its tyrosine kinase activity, respectively, and bevacizumab (Avastin ${ }^{\mathrm{nm}}$ ) blunts VEGF-A (vascular endothelial growth factor A) activity upon binding to the Gly88 residue from the extracellular domain [22]. AS transcript variants have been characterized for all these targets, especially for VEGFA [23-25], and could account for part of the inefficacy of the responses to mAbs. The PIK3/Akt pathway is a major signaling cascade downstream of the receptor tyrosine kinases. In addition, VEGFA expression is regulated by the hypoxia factor HIF-1 $\alpha$. The analyzed genes on this custom microarray include AKT1-3, HER1-4, HIF1A, PIK3CA, PIK3R1-2, VEGFA-D, and PIR that lies close to the VEGFD locus and could be fused to VEGFD upon read through transcription. Collectively, these genes can lead to the assembly of more than 100 mRNAs with protein-coding capacity (http://www.ensembl.org). Hence, the response to targeted anticancer therapy will likely depend, at least in part, on the selection of specific combinations of protein targets derived from AS events.

In order to validate our custom DNA chip, we took advantage of the human lung adenocarcinoma H358 cell line that we previously engineered to conditionally overexpress the pre-mRNA splicing enhancer protein SRSF2, which controls the splicing of VEGFA pre-mRNA [26], but also has a role in transcriptional elongation [27]. Positive results were further validated by specific quantitative RTPCR in both H358 cells and human non-small cell lung carcinoma (NSCLC) samples that we previously showed to over-express the SRSF2 protein [28]. The repercussion of altered splicing on the amount of the HER1/EGFR protein and the response to gefitinib were analyzed in H358 cells.

\section{Results}

Validation of the splice-inducing ability of SRSF2

Using an E1A-based plasmid minigene in transient transfection experiments, we analyzed the splice-inducing ability of SRSF2 (Additional file 1: Figure S1). There was an up-regulation of the $13 \mathrm{~S}$ PCR band associated with a down-regulation of the $9 \mathrm{~S}$ band, indicating that SRSF2 over-expression could modify the balance of E1A-derived transcripts, as originally described [29].

\section{Cross validation with $\mathbf{4 4} \mathrm{k}$ Agilent microarray}

To analyze the gene expression changes triggered by over-expression of SRSF2 in H358 lung cancer cells, we performed an analysis using $44 \mathrm{k}^{\text {Agilent }}{ }^{\mathrm{Tn}}$ microarrays. These data have been deposited in NCBI's Gene Expression Omnibus and are accessible through GEO Series accession number GSE50467. A lot of genes were differentially expressed between SRSF2-over-expressing H358 lung cancer cells and H358 control cells (1,709 deregulated probes; $\geq 2.0 \mathrm{FC}, \mathrm{P}$-value $\leq 0.05$ by $t$-test with FDR; Additional file 2: Table S1), corresponding to $52 \%$ upand $48 \%$ down-regulations. Hence, in addition to its already reported role in the regulation of VEGFA splicing, over-expression of SRSF2 led to the regulation of transcript abundance of many additional genes, including genes present on the $15 \mathrm{k}$ custom chip (Additional file 3: Table S2), as demonstrated with the $44 \mathrm{k} \mathrm{Agilent}^{\mathrm{m}}$ microarrays.

\section{Validation of the labeling method: comparison of the $15 \mathrm{k}$ custom and $\mathbf{4 4} \mathrm{k}$ Agilent microarrays}

The labeled cRNA yield and the specific activity of cyanine3 were examined for each of three labeling experiments (Additional file 4: Table S3). A comparison of the $15 \mathrm{k}$ custom and $44 \mathrm{k}$ commercial microarrays, with respect to Agilent ${ }^{\text {tm }}$ probes present on both chips, was performed in order to validate the use of the labeling method with the $15 \mathrm{k}$ custom microarray. The number of $15 \mathrm{k}$ replicates using Quick Amp labeling was equal to 4 for each condition (control or SRSF2 over-expression), and the number of $44 \mathrm{k}$ replicates was equal to 6 for each condition. We found that 313 Agilent $^{\text {tw }}$ probes (corresponding to $16 \%$ of the total number of Agilent ${ }^{\text {tw }}$ probes on the $15 \mathrm{k}$ chip) were deregulated on the $15 \mathrm{k}$ custom microarray ( $\geq 1.5$ FC, P-value $\leq 0.05)$, among which $310(99 \%)$ had the same type of (up- or down-) regulation on the $44 \mathrm{k}$ 
commercial microarrays (Additional file 5: Table S4). Pearson correlation between expression signals of these 313 common genes led to a coefficient of 0.89 . Therefore, it was considered that Quick Amp labeling was validated for the $15 \mathrm{k}$ custom microarray.

\section{Detection of the mRNA regulation}

We analyzed the expression of the 16 selected genes present in the $15 \mathrm{k}$ custom microarray, considering the expression of all custom probes for each gene (Table 1). Four genes (HER4, PIK3CA, PIK3R1 and VEGFD) were not expressed; five genes (AKT2, AKT3, HER2, PIK3R2 and $V E G F C$ ) were not differentially expressed; five genes (AKT1, HER3, HIF1A, PIR and VEGFB) were slightly down-regulated ( $\leq 1.5 \mathrm{FC}, \mathrm{P}$-value $\leq 0.05$ ); HER1/EGFR was more strongly down-regulated ( $\geq 1.5 \mathrm{FC}, \mathrm{P}$-value $\leq$ 0.05 ), and VEGFA was up-regulated ( $\geq 1.5 \mathrm{FC}$, P-value $\leq$ 0.05) in SRSF2-over-expressing H358 lung cancer cells in comparison to H358 control cells. A good concordance between the $15 \mathrm{k}$ and $44 \mathrm{k}$ microarray results was found: 8 out of the 16 genes present in $15 \mathrm{k}$ custom chip were deregulated on $44 \mathrm{k}$ chips ( $\geq 1.1 \mathrm{FC}$, P-value $\leq 0.05$ ), considering Agilent ${ }^{\mathrm{TM}}$ probes, and showed the same type of regulation on the $15 \mathrm{k}$ chip, considering custom probes (Additional file 3: Table S2).

\section{Regulation events among the expressed genes}

The bioinformatics analysis of the $15 \mathrm{k}$ custom microarray showed that 30 custom probe sets from expressed genes were differentially expressed in SRSF2-over-expressing H358 lung cancer cells in comparison to H358 control cells ( $\geq 1.5$ FC, P-value $\leq 0.05$; Table 2 ). The low expressed deregulated probe sets were not considered. The regulation events corresponded to $70 \%$ down- and 30\% upregulations, mostly affecting cassette exons, but also 5 '-untranslated regions and terminal or donor splice sites, of 9 genes among the 12 expressed genes (AKT2, AKT3, HER1/EGFR, HER2, HER3, HIF1A, PIK3R2, VEGFA and $V E G F B)$. Regulations were associated with a high, medium or low confidence, depending on the regulation of probes close to the deregulated probe sets. A list of supporting evidences (Additional file 6: Table S5) was defined corresponding to the regulations that were not always statistically relevant, but confirmed the deregulation of some probe sets. Consequently, these regulations were associated with a high confidence. On the contrary, the confidence was considered as low if neighboring probes were not deregulated or if their regulation was opposite. The regulations associated with a high fold-change and corresponding to unknown and predicted pre-mRNA splicing events could be of special interest.

\section{Validation of regulation events by real-time polymerase chain reaction}

Quantitative RT-PCR was used to measure the expression of 9 genes deregulated on both the $15 \mathrm{k}$ custom and the $44 \mathrm{k}$ commercial microarrays, and the differential expression of all genes in SRSF2-over-expressing H358 lung

Table 1 Gene expression changes in SRSF2-over-expressing H358 lung adenocarcinoma cells

\begin{tabular}{|c|c|c|c|c|c|c|}
\hline Gene regulation & Gene symbol & Control condition intensity & SRSF2 condition intensity & Regulation & Fold-change & P-value \\
\hline Up-regulated & VEGFA & 9.25 & 9.99 & up & 1.67 & 3.38E-08 \\
\hline Down-regulated & HER1/EGFR & 5.01 & 4.11 & down & 1.87 & $3.65 \mathrm{E}-06$ \\
\hline \multirow[t]{5}{*}{ Slightly down-regulated } & HER3 & 2.33 & 1.78 & down & 1.47 & 3.98E-03 \\
\hline & HIFIA & 6.48 & 6.06 & down & 1.33 & 2.04E-04 \\
\hline & $P I R$ & 7.01 & 6.62 & down & 1.32 & $1.82 \mathrm{E}-03$ \\
\hline & $A K T 1$ & 8.04 & 7.68 & down & 1.28 & 8.15E-05 \\
\hline & VEGFB & 7.84 & 7.48 & down & 1.28 & $2.56 \mathrm{E}-04$ \\
\hline \multirow[t]{5}{*}{ Not regulated } & PIK3R2 & 3.94 & 4.19 & up & 1.19 & $1.62 \mathrm{E}-01$ \\
\hline & AKT3 & 2,00 & 1.91 & down & 1.06 & $6.18 \mathrm{E}-01$ \\
\hline & HER2 & 4.89 & 4.81 & down & 1.05 & 4.01E-01 \\
\hline & AKT2 & 5.81 & 5.74 & down & 1.05 & 5.57E-01 \\
\hline & VEGFC & 5.90 & 5.89 & down & 1.01 & $9.03 \mathrm{E}-01$ \\
\hline \multirow[t]{4}{*}{ Not expressed } & PIK3R1 & 1.35 & 1.89 & up & 1.45 & 3.71E-02 \\
\hline & VEGFD & 0.88 & 0.98 & up & 1.07 & 8.23E-02 \\
\hline & HER4 & 0.65 & 0.69 & up & 1.03 & 4.87E-01 \\
\hline & PIK3CA & 1.79 & 1.78 & down & 1.01 & $8.58 \mathrm{E}-01$ \\
\hline
\end{tabular}

The expression and the regulation of the 16 genes were analyzed on the $15 \mathrm{k}$ custom microarray in SRSF2-over-expressing H358 lung cancer cells in comparison to control cells. Some genes were not expressed; others were not differentially expressed. Five genes were slightly down-regulated ( $\leq 1.5 \mathrm{FC}$, P-value $\leq 0.05)$, and one gene (HER1/EGFR) was more strongly down-regulated ( $\geq 1.5 \mathrm{FC}$, P-value $\leq 0.05)$. Only one gene (VEGFA) was up-regulated in the SRSF2 over-expression condition ( $\geq 1.5 \mathrm{FC}, \mathrm{P}$-value $\leq 0.05)$. 
Table 2 Deregulated probe sets in SRSF2-over-expressing H358 lung adenocarcinoma cells

\begin{tabular}{|c|c|c|c|c|c|c|c|}
\hline Gene symbol & Region name & Region type & Confidence & Regulation & Fold-change & P-value & RT-PCR \\
\hline AKT2 & je14_e15_5p_region & Junction & Low & Down & 1.63 & 1.36E-02 & No \\
\hline AKT3 & je7_e8 & Junction & High & Down & 5.99 & 2.07E-05 & Yes \\
\hline AKT3 & e8 & Exon & High & Down & 4.19 & 4.10E-03 & Yes \\
\hline HER1/EGFR & je16_e19 & Junction & High & Down & 3.66 & $1.42 \mathrm{E}-03$ & Yes \\
\hline HER1/EGFR & predict_exon_1_2-10 & Exon & Medium & Up & 33.98 & $0.00 \mathrm{E}+00$ & No \\
\hline HER1/EGFR & est_1_2 & Exon & Medium & Up & 17.35 & 1.00E-09 & No \\
\hline HER1/EGFR & predict_exon_2_3-1 & Exon & Medium & Up & 4.97 & 5.51E-05 & No \\
\hline HER1/EGFR & e26 & Exon & Medium & Down & 2.64 & $2.30 \mathrm{E}-03$ & No \\
\hline HER1/EGFR & ae1_donor_alter & Donor_alter & Medium & Up & 5.55 & 5.40E-03 & No \\
\hline HER1/EGFR & je14_e15 & Junction & Low & Down & 1.87 & 1.05E-02 & No \\
\hline HER1/EGFR & je12_e13 & Junction & Low & Down & 1.76 & $1.13 \mathrm{E}-02$ & No \\
\hline HER2 & ae10_prom_alter & Prom_alter & Medium & Down & 2.73 & 2.32E-02 & No \\
\hline HER3 & je22_ae23_acceptor_alter_I & Junction & Low & Up & 1.68 & 3.33E-02 & No \\
\hline HIF1A & je10_e11 & junction & High & Down & 1.87 & $1.66 \mathrm{E}-05$ & Yes \\
\hline HIF1A & e10 & Exon & High & Down & 1.62 & $3.65 \mathrm{E}-02$ & Yes \\
\hline HIF1A & e9 & Exon & High & Down & 1.56 & $4.78 \mathrm{E}-02$ & Yes \\
\hline HIF1A & e5 & Exon & Low & Down & 2.07 & 1.23E-02 & No \\
\hline HIF1A & je1_5p_region_ae3_acceptor_alter & Junction & Low & Down & 1.56 & 1.64E-02 & No \\
\hline HIFIA & je14_e16 & Junction & Low & Up & 2.22 & 2.08E-02 & No \\
\hline PIK3R2 & e6 & Exon & High & Down & 1.97 & 7.61E-05 & No \\
\hline PIK3R2 & je5_e6 & Junction & High & Down & 3.95 & $3.98 \mathrm{E}-04$ & No \\
\hline PIK3R2 & je7_e8 & Junction & Low & Down & 1.68 & $2.14 \mathrm{E}-03$ & No \\
\hline PIK3R2 & e9 & Exon & Low & Down & 1.74 & 3.34E-03 & No \\
\hline PIK3R2 & je2_e3 & Junction & Low & Down & 1.58 & 4.36E-02 & No \\
\hline VEGFA & e4_term_alter & Term_alter & High & Up & 10.18 & 7.43E-08 & Yes \\
\hline VEGFA & ae6_donor_alter_2 & Donor_alter & High & Down & 2.44 & 4.18E-07 & Yes \\
\hline VEGFA & jae6_donor_alter_2_e7 & Junction & High & Down & 1.93 & $4.96 \mathrm{E}-03$ & Yes \\
\hline VEGFA & ae7_donor_alter & Donor_alter & High & Up & 1.80 & $6.98 \mathrm{E}-04$ & Yes \\
\hline VEGFA & e7 & Exon & Low & Up & 1.50 & 4.00E-04 & No \\
\hline VEGFB & je2_e3 & Junction & Low & Down & 1.62 & 6.47E-05 & No \\
\hline
\end{tabular}

A list of the 30 differentially expressed and deregulated custom probe sets ( $\geq 1.5 \mathrm{FC}, \mathrm{P}$-value $\leq 0.05)$ from expressed genes among the 16 analyzed genes in SRSF2-over-expressing lung cancer cells in comparison to control cells on the $15 \mathrm{k}$ custom microarray is presented. The regulations were associated with a high, medium or low confidence, depending on the regulation of probes in the vicinity of the deregulated probe sets. According to the results with a high confidence (in bold characters), we expect an up-regulation of exon 7 and a down-regulation of exon 8 for AKT3, a multiple exon skipping for HER1/EGFR, a skipping of both exons 9 and 10 for HIF1A, an alternative polyadenylation in intron 4, and alternative donor sites for exons 6 and 7 for VEGFA.

cancer cells in comparison to $\mathrm{H} 358$ control cells was analyzed with RNA isolated independently from that used for chip hybridization (Additional file 7: Table S6). These results confirmed the validity of our experimental approach used to analyze the $15 \mathrm{k}$ custom microarray. Ten out of the 30 deregulated probe sets were selected according to their high confidence (Table 2), and concerned 4 genes, including AKT3, HER1/EGFR, HIF1A and VEGFA (Figure 1). The results of quantitative RT-PCR experiments are shown in Table 3. Relative mRNA levels were normalized to control gene mRNA levels or a fold-change was calculated comparing to a reference event. For HER1/
$E G F R$, we showed a down-regulation of one of the transcripts (last exon > e20) in SRSF2-over-expressing H358 lung cancer cells in comparison to H358 control cells. For $A K T 3$, we validated the up-regulation of exon 7 and the down-regulation of exon 8; that is because the e7+/e8transcript was over-expressed as compared to the e7+/e8+ transcript including both exons. For HIF1A, the upregulation for two (e9+/e10- and e9-/e10-) of the three alternative transcripts compared to the $\mathrm{e} 9+/ \mathrm{e} 10+$ transcript led us to conclude that both exons 9 and 10 were downregulated. For $V E G F A$, we validated the alternative polyadenylation in intron 4 by an over-expression of the smaller 


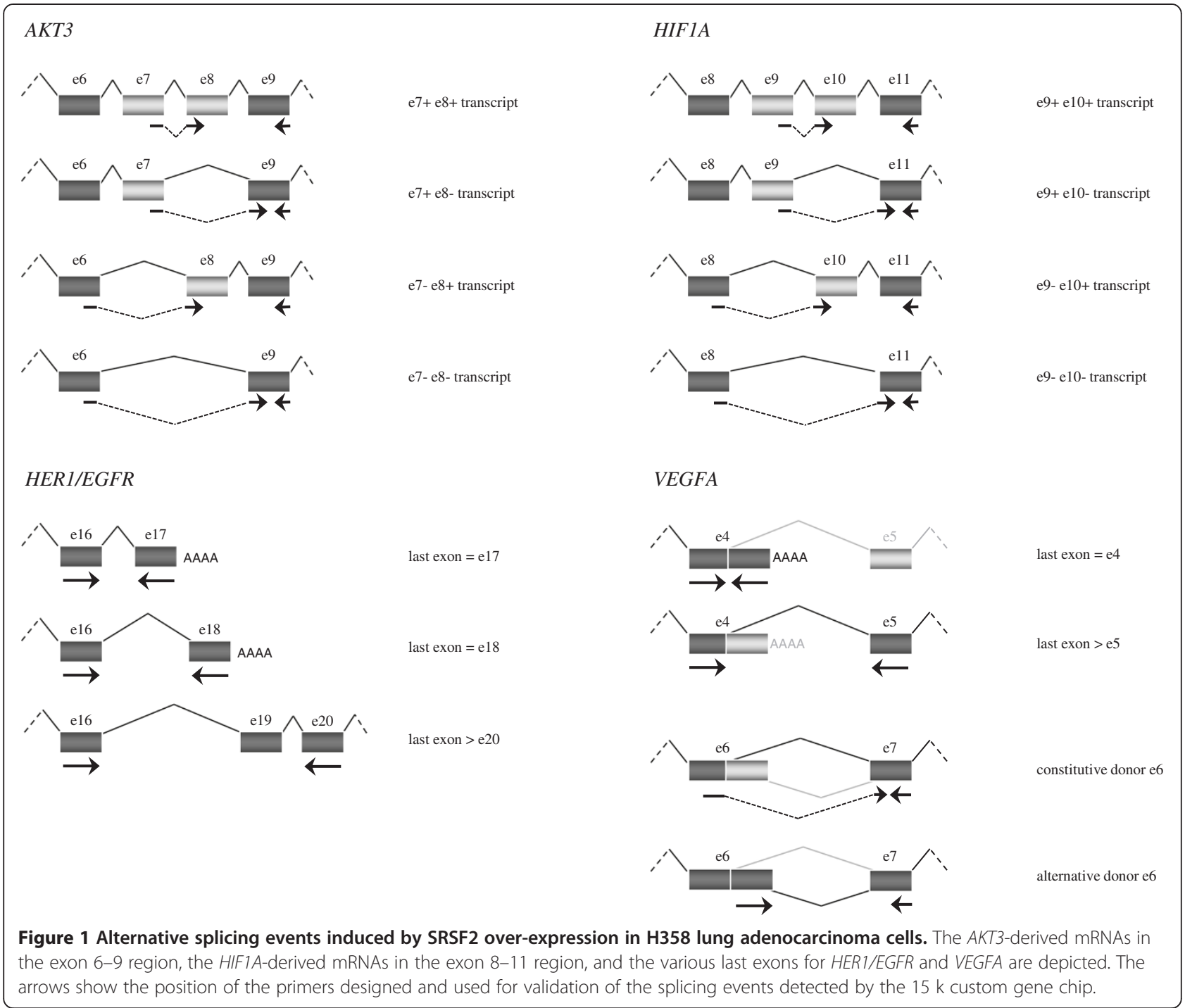

transcript (last exon $=\mathrm{e} 4$ ) in comparison to the longer transcript (last exon > e5). We also confirmed the alternative donor site for the exon 6 by an up-regulation of the "alternative donor e6" transcript in comparison with the "constitutive donor e6" transcript.

\section{HER1/EGFR protein expression analysis}

The $15 \mathrm{k}$ custom microarray predicted multiple exon skipping in the 3' region of HER1/EGFR in SRSF2-overexpressing H358 lung cancer cells, which was confirmed by quantitative RT-PCR. These observations led us to test whether these splicing events would have an impact on the amount of the HER1/EGFR protein. Western blotting analysis was performed using various anti-EGFR antibodies directed against the $\mathrm{N}$-terminal (31G7) or the C-terminal (D38B1) portion of the protein, as well as against the phosphorylated active form of EGFR (P-HER1/ EGFR-Tyr1068). The results demonstrated that SRSF2 overexpression in H358 cells led to a decrease in EGFR protein amount, as detected using all antibodies (Figure 2). These data suggested that SRSF2-regulated EGFR premRNA splicing strongly affects EGFR protein expression.

In addition, H358 cells express a wild-type EGFR protein and are resistant to apoptosis in response to EGFR tyrosine kinase inhibitors such as gefitinib. In order to determine if SRSF2-induced EGFR protein down-regulation could modify the response of $\mathrm{H} 358$ cells to gefitinib, we performed a dose-response of the drug in the presence or absence of SRSF2 induction (Figure 3). As expected, a 24 hours-treatment with gefitinib significantly prevented EGFR-Tyr1068 phosphorylation in these cells, but only partially engaged apoptosis at the higher concentration, which was detected by poly-ADP ribose polymerase (PARP) processing. However, caspase-3 was never activated in gefitinib-treated cells. Of note, at the highest gefitinib concentration, a reduction in the amount of total 
Table 3 Quantitative RT-PCR validation in SRSF2-over-expressing H358 lung adenocarcinoma cells

\begin{tabular}{|c|c|c|c|c|c|}
\hline \multicolumn{6}{|c|}{ SRSF2 Condition vs. Control condition } \\
\hline Gene & Calculation & Transcript & Expression & Observed transcript regulation & Expected transcript regulation \\
\hline \multirow[t]{3}{*}{ HER1/EGFR } & Relative expression & Last exon $=\mathrm{e} 17$ & $\mathrm{n} / \mathrm{a}$ & Not expressed & No expression \\
\hline & & Last exon $=\mathrm{e} 18$ & 0.91 & Not regulated & Over-expression \\
\hline & & Last exon > e20 & 0.42 & Under-expressed & Under-expression \\
\hline \multirow[t]{3}{*}{ AKT3 } & Fold-change & e7+ e8- vs. e7+ e8+ & 1.46 & Over-expression of e7+ e8- & $\begin{array}{l}\text { Over-expression of exon } 7 \text { and } \\
\text { under-expression of exon } 8\end{array}$ \\
\hline & & e7- e8+ vs. e7+ e8+ & -1.19 & No regulation of e7- e8+ & \\
\hline & & e7- e8- vs. e7+ e8+ & $\mathrm{n} / \mathrm{a}$ & No expression of e7- e8- & \\
\hline \multirow[t]{3}{*}{ HIFIA } & Fold-change & e9+ e10- vs. e9+ e10+ & 1.91 & Over-expression of e9+ e10- & Under-expression of exon 10 \\
\hline & & e9- e10+ vs. e9+ e10+ & -1.52 & Under-expression of e9- e10+ & Under-expression of exon 10 \\
\hline & & e9- e10- vs. e9+ e10+ & 1.82 & Over-expression of e9- e10- & $\begin{array}{l}\text { Under-expression of exons } \\
\qquad 9 \text { and } 10\end{array}$ \\
\hline VEGFA & Fold-change & Last exon $=$ e4 vs. last exon $>$ e5 & 18.93 & Over-expression of "last exon = e4" & Over-expression of exon 4 \\
\hline VEGFA & Fold-change & $\begin{array}{c}\text { Alternative vs. constitutive } \\
\text { donor e6 }\end{array}$ & 14.46 & $\begin{array}{c}\text { Over-expression of "alternative } \\
\text { donor e6" }\end{array}$ & $\begin{array}{c}\text { Over-expression of alternative } \\
\text { donor }\end{array}$ \\
\hline
\end{tabular}

The regulation of the 10 selected deregulated custom probe sets was analyzed by quantitative RT-PCR in SRSF2-over-expressing lung cancer cells in comparison to control cells. Relative mRNA levels were normalized to that of beta-2-microglobulin or a fold-change was calculated comparing to a reference event. The cut-off value was equal to 1.40 . n/a: not available.

EGFR together with the appearance of protein bands of smaller sizes was observed when using the 31G7 antibody mainly. These data suggested that EGFR could be processed in response to high gefitinib doses. Importantly, when SRSF2 was overexpressed in gefitinib-treated cells,

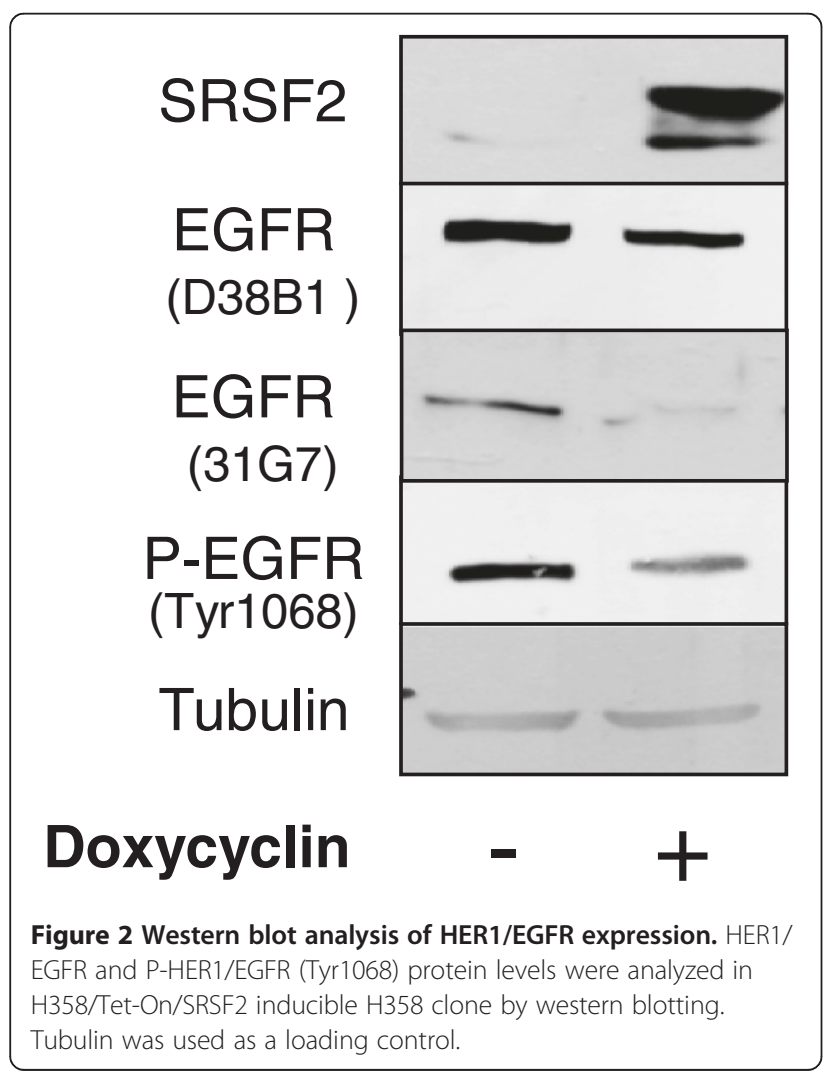

the decrease in EGFR protein amount was more pronounced and apoptosis was strongly engaged, as evidenced by procaspase- 3 and PARP cleavages (Figure 3). This result indicated that SRSF2, through its ability to control EGFR protein expression, sensitizes H358 cells to the apoptosis induced by EGFR tyrosine kinase inhibitors.

Alternative splicing events in lung cancer biopsy samples Finally, we aimed at extending some of our in vitro data to cancer tissues. For this purpose, we took advantage of

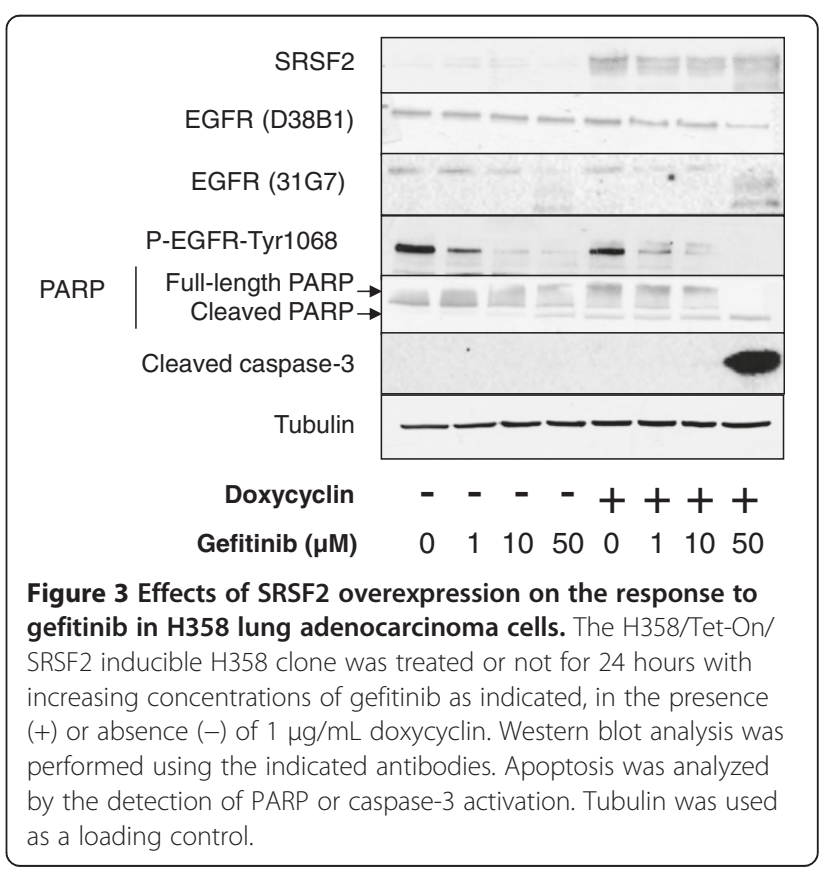


the cancer-associated over-expression of SRSF2, as it may occur in NSCLC [28]. SRSF2 and phospho-SRSF2 expression scores (0-300) were established in 10 NSCLC biopsy samples (Table $4 \mathrm{~A}$ ) by multiplying the percentage of labeled tumor cells ( 0 to $100 \%$ ) by the staining intensity (0, null; 1 , low; 2 , moderate; 3 , strong). Interestingly, the three NSCLC samples with the highest SRSF2 and phospho-SRSF2 scores all displayed a drop in the HER1/ EGFR "last exon > e20" transcript, as determined by quantitative RT-PCR, similarly to what occurred in lung cancer cells. We also analyzed the occurrence of the $A K T 3$, HIF1A and VEGFA splicing events in NSCLC biopsy samples (Table 4B). For several samples, we observed an overexpression of exon 7 and an under-expression of exon 8 of $A K T 3$, and an over-expression of exon 4 and alternative exon 6 donor splice site for VEGFA. Although the relationships between SRSF2 status and these splicing events were less clear in these cases, maybe owing to the small number of samples, these data validated, in cancer samples, some of the pre-mRNA splicing events detected in the SRSF2-over-expressing H538 cell line. The results were inconclusive for $H I F 1 A$, possibly reflecting heterogeneity among the NSCLC samples with respect to expression of this gene.

\section{Discussion}

In this study, we designed a custom gene expression microarray amenable to the study of alternative pre-mRNA splicing (AS) events of a selection of genes involved in the response to targeted anticancer therapies. This approach was preferred to commercial microarrays, such as the $\mathrm{Hu}$ man Exon 1.0 ST arrays (Affymetrix ${ }^{\mathrm{Tm}}$ ) because it allowed a deeper analysis of AS, in this case of a small number of genes highly relevant from a clinical standpoint. Indeed, it is clear that our custom splice-sensitive microarray could theoretically detect many more events than Affymetrix ${ }^{\text {Tx }}$

Table 4 Quantitative RT-PCR validation in non small cell lung carcinoma samples

A

Sample

SRSF2 Protein Score

Phospho-SRSF2 Protein Score

B

\begin{tabular}{|c|c|c|c|c|c|c|c|c|c|c|c|c|c|}
\hline Gene & Calculation & Transcript & 1 & 2 & 3 & 4 & 5 & 6 & 7 & 8 & 9 & 10 & $\begin{array}{l}\text { Observed Transcript } \\
\text { Regulation }\end{array}$ \\
\hline \multirow[t]{3}{*}{ HER1/EGFR } & \multirow[t]{3}{*}{ Relative expression } & Last exon $=\mathrm{e} 17$ & $\mathrm{n} / \mathrm{a}$ & $n / a$ & $n / a$ & $\mathrm{n} / \mathrm{a}$ & 7.17 & $\mathrm{n} / \mathrm{a}$ & $\mathrm{n} / \mathrm{a}$ & 16.15 & 2.52 & $\mathrm{n} / \mathrm{a}$ & $\begin{array}{l}\text { Not expressed or } \\
\text { over-expressed }\end{array}$ \\
\hline & & Last exon $=\mathrm{e} 18$ & 2.69 & $n / a$ & 1.86 & 2.27 & 5.13 & 6.86 & 2.23 & 15.16 & 3.01 & 66.18 & Over-expressed \\
\hline & & Last exon > e20 & 0.15 & 0.29 & 0.20 & 6.71 & 6.99 & 21.45 & 0.10 & 5.39 & 2.46 & $\mathrm{n} / \mathrm{a}$ & $\begin{array}{l}\text { Over-expressed } \\
\text { or under-expressed }\end{array}$ \\
\hline \multirow[t]{3}{*}{ AKT3 } & \multirow[t]{3}{*}{ Fold-change } & e7+ e8- vs. e7+ e8+ & 0.84 & 1.46 & 1.16 & 1.37 & 1.08 & 1.76 & 1.29 & 1.47 & 1.47 & 2.28 & $\begin{array}{l}\text { Over-expression or } \\
\text { no regulation }\end{array}$ \\
\hline & & e7- e8+ vs. e7+ e8+ & $n / a$ & 1.33 & $n / a$ & 1.35 & $\mathrm{n} / \mathrm{a}$ & $\mathrm{n} / \mathrm{a}$ & $\mathrm{n} / \mathrm{a}$ & 0.38 & $\mathrm{n} / \mathrm{a}$ & $\mathrm{n} / \mathrm{a}$ & $\begin{array}{l}\text { Low expression of } \\
\text { e7- e8+ }\end{array}$ \\
\hline & & e7- e8- vs. e7+ e8+ & $n / a$ & $n / a$ & $n / a$ & $\mathrm{n} / \mathrm{a}$ & $\mathrm{n} / \mathrm{a}$ & $\mathrm{n} / \mathrm{a}$ & $\mathrm{n} / \mathrm{a}$ & $\mathrm{n} / \mathrm{a}$ & $\mathrm{n} / \mathrm{a}$ & $\mathrm{n} / \mathrm{a}$ & $\begin{array}{l}\text { No expression of } \\
\text { e7- e8- }\end{array}$ \\
\hline \multirow[t]{3}{*}{ HIFIA } & \multirow[t]{3}{*}{ Fold-change } & e9+ e10- vs. e9+ e10+ & 0.63 & 0.54 & 1.63 & 1.40 & 0.79 & 1.77 & 0.87 & 1.22 & 1.20 & 1.15 & $\begin{array}{l}\text { Depending on biopsy } \\
\text { samples }\end{array}$ \\
\hline & & e9- e10+ vs. e9+ e10+ & 1.87 & $n / a$ & $n / a$ & 1.06 & $\mathrm{n} / \mathrm{a}$ & $\mathrm{n} / \mathrm{a}$ & $\mathrm{n} / \mathrm{a}$ & $\mathrm{n} / \mathrm{a}$ & 1.14 & 1.77 & $\begin{array}{l}\text { Depending on biopsy } \\
\text { samples }\end{array}$ \\
\hline & & e9- e10- vs. e9+ e10+ & 0.57 & 0.73 & 1.55 & 1.49 & 0.84 & 1.88 & 0.79 & 1.99 & 0.76 & 1.01 & $\begin{array}{l}\text { Depending on biopsy } \\
\text { samples }\end{array}$ \\
\hline VEGFA & Fold-change & $\begin{array}{l}\text { Last exon }=\text { e } 4 \text { vs. } \\
\text { Last exon }>\text { e5 }\end{array}$ & 1.33 & 1.21 & 1.54 & 1.92 & 0.84 & 2.22 & 10.37 & 2.73 & 1.21 & 1.09 & $\begin{array}{l}\text { Over-expression or } \\
\text { no regulation }\end{array}$ \\
\hline VEGFA & Fold-change & $\begin{array}{l}\text { Alternative vs. } \\
\text { constitutive donor e6 }\end{array}$ & 3.50 & 3.33 & 5.25 & 3.99 & $\mathrm{n} / \mathrm{a}$ & $\mathrm{n} / \mathrm{a}$ & 19.22 & 14.29 & n/a & 45.68 & Over-expression \\
\hline
\end{tabular}

The regulation of the 10 selected deregulated custom probe sets was analysed by quantitative RT-PCR in 10 non small cell lung carcinoma - normal sample pairs (patients numbered from 1 to 10). SRSF2 protein expression levels in biopsy samples were analysed by immunohistochemistry in a previous study. A score (0-300) was established for SRSF2 and phosphorylated SRSF2 (P-SRSF2). Patients with scores $\geq 150$ and $>175$ were those over-expressing SRSF2 and P-SRSF2 proteins respectively, as compared to normal lung tissues. Patients in bold characters over-expressed both proteins. n/a: not available.

Relative mRNA levels were normalised to that of beta-2-microglobulin or a fold-change was calculated comparing to a reference event. The cut-off value was equal to 1.40. n/a: not available. Patients in bold characters over-expressed both SRSF2 and phospho-SRSF2 proteins (see Table 4A). 
Exon Arrays (Table 5), considering probe length, probe number and, especially, exon-exon junction probes, which were not present on Affymetrix ${ }^{\mathrm{Tm}}$ Exon Arrays. At a practical level, several high confidence events revealed, thanks to exon-exon junction probes, specific splicing events (Table 2). For example AKT3 je7_e8, HER1/EGFR je16_e19 or HIF1A je10_e11 junction-specific events would have been undetected on Affymetrix ${ }^{\mathrm{Tm}}$ arrays. In addition, selecting only the high confidence events, the regulations observed through the chip analysis were confirmed by quantitative RT-PCR, emphasizing the robustness of both the technical and the analytical tools used in this study. Nevertheless, we anticipate that RNA-Seq methodologies will probably soon be another, reliable, means for characterizing AS throughout the transcriptome [30,31].

We are aware of only one study that used a designed chip to analyze the occurrence of splicing variants which, in that case, corresponded to AS events from a single gene, CIZ1, encoding a Cip1-interacting zinc finger protein [32]. This approach led to the identification of a splice variant that may be specific for pediatric cancer. There is an absolute need for predictive biomarkers of therapeutic responses, especially targeted anticancer therapies, as many patients do not respond or acquire resistance. For instance, VEGF-A isoforms may not respond identically to antiVEGF-A mAbs (bevacizumab). In fact, the co-occurrence of both pro-angiogenic (VEGF- $\mathrm{A}_{\mathrm{xxx}}$ ) and anti-angiogenic (VEGF- $\left.A_{x x x} b\right)$ splice isoforms might restrict the therapeutic response [33-37]. In addition, the occurrence of soluble EGFR isoforms, as detected in meningiomas [38], presumably unresponsive to tyrosine kinase inhibitor therapy, might also dampen the therapeutic response. Furthermore, an exon 4-lacking EGFR variant mRNA was associated with an increased metastatic potential, a molecular event that would likely have been detected with our splice-sensitive microarray [39]. Hence, in addition to providing a comprehensive picture of splicing events and potential therapy response, our chip could also help predicting clinical outcome, based on the detection of prometastatic mRNA species. Nevertheless, beyond the concept, more predictive studies should be performed to make our splice-screening methodology an efficient therapy selecting option.

We showed that SRSF2 has an effect on transcriptional regulation and on AS of several genes analyzed in this study. Notably, SRSF2 over-expression modified HER1/
EGFR and VEGFA expression in H358 lung cancer cells. Using patient-derived material, we observed that strong SRSF2 over-expression in NSCLC is associated with splicing alterations of the HER1/EGFR and VEGFA transcripts, as predicted from the results in the SRSF2-over-expressing H358 lung cancer cell line. In addition, HER1/EGFR splicing events have also been identified in lung adenocarcinomas [40], lending support to our results. The observation that the increase in SRSF2 protein level induced massive procaspase-3 cleavage when associated with gefitinib in H358 cells, which express wild-type and non amplified EGFR protein, may be particularly relevant for patients with lung adenocarcinomas without EGFR mutations, as one of the challenges is to understand why only some of them respond to EGFR tyrosine kinase inhibitors.

The expression level of HER1 mRNA, measured through analysis of the $44 \mathrm{k} \mathrm{Agilent}^{\mathrm{TM}}$ chip, and the western blotting analysis of the protein, showed a good correlation in response to SRSF2 over-expression. In this specific case, use of the custom $15 \mathrm{k}$ chip would not have been more predictive. Nevertheless, it is doubtless that AS, analyzed globally for all genes from the chip, will provide a lot more information on both transcript abundance and structure, allowing defining a prognostic indicator of response to antibody-based therapy [41]. An important challenge will be to develop specific antibodies to detect full length or modified proteins encoded by AS-derived transcripts. Alternatively, mass spectrometry proteomics could be used to identify and quantify such proteins [42]. The custom chip analysis could thus ideally supplement immunologyor proteomics-based approaches aimed at looking for the expression of protein targets. Our DNA gene chip could also be used to analyze the effect of other triggers, such as over-expression or silencing of other splice-modifying proteins, or treatment with drugs, especially anticancer drugs, which can profoundly affect pre-mRNA splicing $[3,43]$.

\section{Conclusion}

Our results describe, for the first time, the design and validation of a custom splice-sensitive microarray to detect AS events occurring in genes involved in the response to targeted anticancer therapies. Such an experimental setup could help clinicians choose anticancer drugs depending on the tumor expression of gene targets with proficient mRNA structures.

Table 5 Comparison of gene coverage between the custom gene chip and the Affymetrix ${ }^{\mathrm{Tm}}$ Exon Array

\begin{tabular}{lccccr}
\hline Gene & \multicolumn{2}{c}{ Custom array (present study) } & & \multicolumn{2}{c}{ Affymetrix $^{\text {TM }}$ Exon array } \\
\cline { 2 - 3 } \cline { 5 - 6 } & Nb probes (exonic/junction) & Average probe length (bp) & & Nb probes (exonic/junction) & Average probe length (bp) \\
\hline HIF1A & $123(85 / 38)$ & 42.4 & & $80(80 / 0)$ & 25.0 \\
VEGFA & $90(64 / 26)$ & 42.3 & & $60(60 / 0)$ & 25.0 \\
\hline
\end{tabular}

The numbers of probes and their average length are shown for both the HIF1A and VEGFA genes. 


\section{Methods}

\section{Custom microarray design}

A custom microarray was designed taking advantage on the $15 \mathrm{k}$ Whole Human Genome microarray, available from Agilent $^{\mathrm{TM}}$ (Agilent, Massy, France). Among the Agilent ${ }^{\mathrm{TM}}$ probes initially loaded on the chip, 11,881 (Additional file 8: Figure S2) were substituted by custom oligonucleotides, corresponding to known and predicted exons, introns and junctions of 16 selected genes, among which there were members of the AKT (AKT1, AKT2, AKT3), HER (HER1) EGFR, HER2, HER3, HER4), PIK3 (PIK3CA, PIK3R1, PIK3R2) and VEGF (VEGFA, VEGFB, VEGFC, VEGFD) families, but also HIF1A and PIR. On the microarray, the majority (60\%) of custom probes had a length of $40 \mathrm{bp}$; some were shorter (down to $22 \mathrm{bp} ; 8 \%$ ); others were longer (up to $50 \mathrm{bp} ; 26 \%$ ), which was mostly the case of the probes for exon-exon junctions. This was especially important to insure a good detection of alternative 5' and 3' splice sites, i.e. alternative exon boundaries. Each custom probe length was adjusted to $60 \mathrm{bp}$ with linker addition. The other 3,863 probes on the microarray corresponded to replicates of commercial Agilent ${ }^{\text {TM }}$ probes (genes or controls). As a whole, the expression of 1,967 distinct genes can be analyzed with our chip.

\section{Cell culture and RNA extraction}

The H358 human lung adenocarcinoma cell line was cultured as described previously [44]. The H358/Tet-On/ SRSF2 inducible clone, conditionally over-expressing the SRSF2 splicing factor under the control of a Tet-responsive promoter, has been described previously $[44,45]$. SRSF2 over-expression was induced upon 24 hours treatment with $1 \mu \mathrm{g} / \mathrm{mL}$ doxycycline (Additional file 9: Figure S3). Gefitinib was added to the cells at the indicated final concentrations for 24 hours. Total RNA was isolated using the Trizol reagent (Invitrogen, Cergy-Pontoise, France), according to the manufacturer's instructions. RNA purity and integrity were determined by measuring the optical density ratio (A260/A280) and the RNA integrity number (RIN) using the RNA 6000 Nano LabChip (Agilent ${ }^{\mathrm{TM}}$ ) and the 2100 Bioanalyzer $\left(\right.$ Agilent $\left.^{\mathrm{Tm}}\right)$. Only RNA samples with a $28 \mathrm{~S} / 18 \mathrm{~S}$ ratio $>1.0$ and $\mathrm{RIN} \geq 7.0$ were used for microarray analyses.

\section{Plasmid transfection and minigene analysis}

An E1A reporter minigene-containing plasmid (pXJ41E1A) to study the effect of splice modifier proteins was used to further validate the effect of SRSF2 protein overexpression. The plasmid was transfected using Lipofectamine 2000 (Invitrogen). Cells were harvested 24 hours after transfection, and total RNA was extracted using the RNeasy Mini kit (Qiagen, Courtabœuf, France), according to the manufacturer's instructions. The RNAs (200 ng) were further used for first-strand cDNA synthesis with the High-Capacity cDNA Reverse Transcription kit (Applied Biosystems, Courtabœuf, France). For the detection of E1A splice variants, PCR amplification was performed using primers 5'-TTT-GGA-CCA-GCTGAT-CGA-AG-3' and 5' -AAG-CTT-GGG-CTG-CAGGTC-GA-3', and PCR products were analyzed by agarose gel electrophoresis.

\section{Microarray hybridization}

Analyses of the H358/Tet-On/SRSF2 mRNA content were performed on both the $15 \mathrm{k}$ custom microarray and the $44 \mathrm{k}$ Whole Human Genome microarray (Agilent ${ }^{\mathrm{Tm}}$ ) that contains roughly 41,000 probes, providing full coverage of human transcripts. Double-stranded cDNA was synthesized from $500 \mathrm{ng}$ of total RNA using the Quick Amp Labeling kit, One-color, as instructed by the manufacturer (Agilent ${ }^{\mathrm{TM}}$ ). Labeling with cyanine3CTP, fragmentation of cRNA, hybridization and washing were performed according to the manufacturer's instructions. The microarrays were scanned and the data were extracted with the Agilent ${ }^{\mathrm{TM}}$ Feature Extraction Software.

\section{Gene expression analysis}

The bioinformatics analysis of the $15 \mathrm{k}$ custom microarray data and the comparison of $15 \mathrm{k}$ chip results with $44 \mathrm{k}$ commercial chip results were performed by GenoSplice technology ${ }^{\mathrm{Tm}}$. Concerning the $15 \mathrm{k}$ custom microarray data analysis, data were normalized using median normalization based on Agilent ${ }^{\mathrm{TM}}$ control genes. Gene expression level was assessed using constitutive probes only (i.e., probes targeting regions that are not known to be alternative regions). For each gene of interest, all possible splicing patterns were defined and analyzed. All types of alternative events can be analyzed: alternative first exons, alternative terminal exons, cassette exons, mutually exclusive exons, alternative 5' donor splice sites, alternative $3^{\prime}$ acceptor splice sites, and intron retentions. Analyses were performed using unpaired Student's $t$-test on the splicing-index as previously described $[46,47]$. Results were considered statistically significant for unadjusted P-values $\leq 0.05$ and fold-changes $\geq 1.5$. After bioinformatics analysis of microarray data, a manual inspection using the GenoSplice EASANA ${ }^{\mathrm{TM}}$ interface was conducted to select highconfidence events. An alternative $44 \mathrm{k}$ bioinformatics analysis was carried out. Raw gene expression data were imported into the GeneSpring GX 11.0.2 software program $\left(\right.$ Agilent $\left.^{\mathrm{Tw}}\right)$. Genes with missing values in more than $25 \%$ of the samples were excluded from the analysis. A 2-fold cut-off difference was applied to select the up- and down-regulated genes (P-value $\leq 0.05$ by $t$ test with Benjamini-Hochberg false discovery rate). 


\section{Real-time polymerase chain reaction analysis}

Regulation events detected in the $15 \mathrm{k}$ custom and $44 \mathrm{k}$ commercial microarrays were analyzed by quantitative RT-PCR using RNA isolated from cell preparations separate from those originally used for microarray hybridization. Reverse transcription was performed as instructed by the manufacturer (Applied Biosystems), as described previously, and quantitative RT-PCR was conducted using the SYBR GREEN PCR Master Mix (Applied Biosystems), according to the manufacturer's instructions, with an ABI 7300 real-time PCR system (Applied Biosystems). All determinations were performed in duplicate, normalized against beta-2-microglobulin or GAPDH as internal control genes. These reference transcripts were found to be stable when surveyed in several cell culture systems (data not shown). The results were expressed as the relative gene expression using the $\Delta \Delta \mathrm{Ct}$ method [48]. The fold-change was also calculated comparing to a reference event. The sequences of the primers used for the $15 \mathrm{k}$ custom microarray validation are presented in Additional file 10: Table S7.

\section{Protein extraction and western blotting analysis}

The antibodies used in this study included anti-SRSF2 (4 F11) from Euromedex, anti-EGFR (31G7) from Invitrogen, anti-HER1/EGFR (D38B1) and anti-P-HER1/EGFR (Tyr1068) (D7A5) from Cell Signaling. For immunoblotting, cells were lysed in RIPA buffer $[150 \mathrm{mM} \mathrm{NaCl}$, $50 \mathrm{mM}$ Tris $\mathrm{HCl} \mathrm{pH} \mathrm{8,0.1 \%} \mathrm{SDS,} \mathrm{1 \%} \mathrm{Nonidet} \mathrm{P40,} \mathrm{0.5 \%}$ Na deoxycholate, $0.1 \mathrm{mM}$ PMSF, $2.5 \mu \mathrm{g} / \mathrm{mL}$ pepstatin, 10 $\mu \mathrm{g} / \mathrm{mL}$ aprotinin, $5 \mu \mathrm{g} / \mathrm{mL}$ leupeptin, $0.2 \mathrm{mM} \mathrm{Na}_{3} \mathrm{VO}_{4}$ ] for 30 minutes on ice and pelleted. Protein concentration was determined using the Biorad DC protein assay. Proteins $(40-80 \mu \mathrm{g})$ were then separated in 10\% SDS-PAGE gels and electroblotted onto PVDF membranes. Membranes were incubated overnight at $+4^{\circ} \mathrm{C}$ with primary antibodies and proteins were detected using horseradish peroxidase-conjugated goat antibodies (Jackson Immunoresearch Laboratories, West Grove, PA, USA). After washing, the blots were revealed using the ECL chemiluminescence method (Amersham, Les Ulis, France). Tubulin was used as a loading control.

\section{Human samples}

Tissue samples were collected from resection of lung tumors, and stored for scientific research in a biological resource repository (Centre de Ressources Biologiques, CHU Albert Michallon, Grenoble Hospital). National ethical guidelines were followed. All patients enrolled provided written informed consent. Tissue banking and research conduct was approved by the Ministry of Research (approval AC-2010-1129) and by the regional IRB
(CPP 5 Sud Est). Protein and RNA samples were isolated and analysed as described above.

\section{Additional files}

Additional file 1: Figure S1. E1A splicing assay in response to SRSF2 over-expression. Following transient cell transfection with a SRSF2 expression plasmid, E1A splice-derived PCR products were electrophoresed through a $2 \%$ agarose gel and stained with ethidium bromide. The characteristic PCR products (9S-13S) are shown.

Additional file 2: Table S1. Deregulated genes on the 44k Agilent $^{\mathrm{TM}}$ microarray in H358 SRSF2-over-expressing cells. Significantly down- and up-regulated genes in SRSF2-over-expressing H358 lung cancer cells in comparison to H358 control cells are listed ( $\geq 2.0 \mathrm{FC}, \mathrm{P}$-value $\leq 0.05$ by t-test with FDR).

Additional file 3: Table S2. Regulation of the 16 selected genes on the 44k Agilent ${ }^{\text {TM }}$ microarray in SRSF2-over-expressing $\mathrm{H} 358$ cells. The results for the 8 deregulated genes in SRSF2-over-expressing H358 lung cancer cells in comparison to $\mathrm{H} 358$ control cells on the $44 \mathrm{k}$ microarrays are shown ( $\geq 1.1 \mathrm{FC}$, P-value $\leq 0.05$ by $t$-test with FDR). The $44 \mathrm{k}$ microarray results for the 8 deregulated genes showed a good concordance with the $15 \mathrm{k}$ custom microarray results.

Additional file 4: Table S3. Labeling efficiency for hybridization of the $15 \mathrm{k}$ custom microarray. The labeled CRNA yield and specific activity of cyanine3 are shown for each of the three labeling experiments performed. The cRNA yield should be superior to $1.65 \mu \mathrm{g}$, and the specific activity superior to $9.0 \mathrm{pmol}$ cyanine3 per $\mu \mathrm{g}$ CRNA. The number of 15k replicates using Quick Amp labeling was 4 for each condition (control or SRSF2 over-expression), and the number of $44 \mathrm{k}$ replicates was 6 (i.e. 2 for each of the three labeling) for each condition.

Additional file 5: Table S4. Comparison of the 15k custom and $44 \mathrm{k}$ Agilent $^{\mathrm{TM}}$ microarray results. The results are shown for the Agilent ${ }^{\mathrm{TM}}$ probes present on both chips: 313 probes were deregulated in SRSF2-over-expressing H358 lung cancer cells in comparison to H358 control cells on the $15 \mathrm{k}$ custom chip ( $\geq 1.5$ FC, P-value $\leq 0.05$ ), and 310 had the same type of regulation, considering statistically relevant and not statistically relevant regulations on the 44k chip (same type of regulation $=1$; other type of regulation $=0$ ).

Additional file 6: Table S5. Supporting evidences. The list of supporting evidences that confirmed the regulation of some probe sets in SRSF2-over-expressing H358 lung cancer cells in comparison to H358 control cells is presented.

Additional file 7: Table S6. Quantitative RT-PCR validation. Common regulation events between the $15 \mathrm{k}$ custom and $44 \mathrm{k} \mathrm{Agilent}^{\mathrm{TM}}$ microarrays were validated by quantitative RT-PCR in SRSF2-over-expressing H358 lung cancer cells in comparison to $\mathrm{H} 358$ control cells. Relative mRNA levels were normalized to that of GAPDH.

Additional file 8: Figure S2. Design of the custom 15k gene chip. The chip was designed on the backbone of the Agilent ${ }^{\text {TM }} 15 \mathrm{k}$ whole-genome microarray. The majority of the probes correspond to custom oligonucleotides, i.e. to both known and predictable sequences of exons, introns and junctions of 16 genes selected for their biological interest in the response to targeted anticancer therapies: AKT1-3, HER1-4, HIF1A, PIK3CA, PIK3R1-2, VEGFA-D and PIR. The resolution of the custom microarray was decreased in comparison to the Human Exon 1.0 ST array (Affymetrix ${ }^{\mathrm{TM}}$ ) from 5 million to 12,000 probes, but the number of probes per gene was largely increased, from an average of 45 to an average of 185 probes per gene. The expression of 1,967 distinct genes can also be analyzed thanks to commercial Agilent ${ }^{\mathrm{TM}}$ probes.

Additional file 9: Figure S3. Western blot analysis of SRSF2 expression. SRSF2 protein level was analyzed in H358/Tet-On/SRSF2 inducible clone by western blotting with the mAb104 monoclonal antibody that recognizes several phosphorylated SR proteins (SRSF2-6). SRSF2 mRNA level was also analyzed by quantitative RT-PCR (data not shown). Relative mRNA level was normalized to that of GAPDH. An 8-fold over-expression 
of SRSF2 mRNA was observed in SRSF2-over-expressing lung cancer cells in comparison to control cells.

Additional file 10: Table S7. Primers for validation. The sequences of the primers used for the $15 \mathrm{k}$ custom microarray validation are presented.

\section{Abbreviations}

AS: Alternative pre-mRNA splicing; FC: Fold-change; FDR: BenjaminiHochberg false discovery rate; mAbs: monoclonal antibodies; NMD: nonsense mediated decay; NSCLC: Non-small cell lung carcinoma.

\section{Competing interests}

The authors declare that they have no competing interests.

\section{Authors' contributions}

MP performed the RT-PCR validation of microarray hybridization results, performed the E1A plasmid transfection and RT-PCR analysis, and drafted the manuscript. BS conducted the microarray experiments. BE developed the SRSF2-over-expressing lung cancer cells, and performed the western blotting experiments. PDLG designed the $15 \mathrm{k}$ custom microarray, and performed the bioinformatics analysis of the data. LC coordinated the study, assisted with the design of experiments, and drafted the manuscript. All authors read and approved the final manuscript.

\section{Acknowledgements}

We thank Dr. Pascal Loyer for his gift of the E1A plasmid minigene, and Dr Sandrine Jacolot for her help with analysis of the microarray data. MP was recipient of a fellowship from the Région Bretagne (ARED). This work was supported by the INSERM, the Université de Bretagne Occidentale, the Ligue Contre le Cancer (Comité du Finistère), and the Biolntelligence program.

\section{Author details}

'UMR INSERM U1078-UBO, Equipe ECLA, Faculté de Médecine, 22 Avenue Camille Desmoulins, 29200 Brest, France. ${ }^{2}$ Centre de Recherche INSERM U823, Université Joseph Fourier, Equipe 2 Bases Moléculaires de la Progression des Cancers du Poumon, Institut Albert Bonniot, Domaine de la Merci, Rond-Point de la Chantourne, 38706 La Tronche Cedex, France. ${ }^{3} \mathrm{IUH}$, Centre Hayem, 1 Avenue Claude Vellefaux, 75010 Paris, France.

Received: 30 August 2013 Accepted: 9 January 2014

Published: 15 January 2014

\section{References}

1. Wang ET, Sandberg R, Luo S, Khrebtukova I, Zhang L, Mayr C, Kingsmore SF, Schroth GP, Burge CB: Alternative isoform regulation in human tissue transcriptomes. Nature 2008, 456:470-476.

2. Nilsen TW, Graveley BR: Expansion of the eukaryotic proteome by alternative splicing. Nature 2010, 463:457-463.

3. Dutertre M, Sanchez G, De Cian M-C, Barbier J, Dardenne E, Gratadou L, Dujardin G, Le Jossic-Corcos C, Corcos L, Auboeuf D: Cotranscriptional exon skipping in the genotoxic stress response. Nat Struct Mol Biol 2010, 17:1358-1366.

4. Hallegger $M$, Llorian $M$, Smith CWJ: Alternative splicing: global insights. FEBS J 2010, 277:856-866.

5. David CJ, Manley JL: Alternative pre-mRNA splicing regulation in cancer: pathways and programs unhinged. Genes Dev 2010, 24:2343-2364.

6. Akgul C, Moulding DA, Edwards SW: Alternative splicing of Bcl-2-related genes: functional consequences and potential therapeutic applications. Cell Mol Life Sci 2004, 61:2189-2199.

7. Miura K, Fujibuchi W, Unno M: Splice variants in apoptotic pathway. Exp Oncol 2012, 34:212-217.

8. Schwerk C, Schulze-Osthoff K: Regulation of apoptosis by alternative pre-mRNA splicing. Mol Cell 2005, 19:1-13.

9. Maquat LE: Nonsense-mediated mRNA decay: splicing, translation and mRNP dynamics. Nat Rev Mol Cell Biol 2004, 5:89-99.

10. Isken O, Maquat LE: The multiple lives of NMD factors: balancing roles in gene and genome regulation. Nat Rev Genet 2008, 9:699-712.

11. Gardina PJ, Clark TA, Shimada B, Staples MK, Yang Q, Veitch J, Schweitzer A, Awad T, Sugnet $C$, Dee $S$, et al: Alternative splicing and differential gene expression in colon cancer detected by a whole genome exon array. BMC Genomics 2006, 7:325.
12. Mojica W, Hawthorn L: Normal colon epithelium: a dataset for the analysis of gene expression and alternative splicing events in colon disease. BMC Genomics 2010, 11:5.

13. Xuan J, Yu Y, Qing T, Guo L, Shi L: Next-generation sequencing in the clinic: promises and challenges. Cancer Lett 2012, 340:248-295.

14. Wang Z, Gerstein M, Snyder M: RNA-Seq: a revolutionary tool for transcriptomics. Nat Rev Genet 2009, 10:57-63.

15. Mutz K-O, Heilkenbrinker A, Lönne M, Walter J-G, Stahl F: Transcriptome analysis using next-generation sequencing. Curr Opin Biotechnol 2013, 24:22-30.

16. Lindner R, Friedel CC: A comprehensive evaluation of alignment algorithms in the context of RNA-Seq. PLOS ONE 2012, 7:e52403.

17. Trapnell C, Hendrickson DG, Sauvageau M, Goff L, Rinn JL, Pachter L: Differential analysis of gene regulation at transcript resolution with RNA-seq. Nat Biotechnol 2012, 31:46-53.

18. Xu W, Seok J, Mindrinos MN, Schweitzer AC, Jiang H, Wilhelmy J, Clark TA, Kapur $K$, Xing Y, Faham M, et al: Human transcriptome array for highthroughput clinical studies. Proc Natl Acad Sci 2011, 108:3707-3712.

19. Glas AM, Floore A, Delahaye LJMJ, Witteveen AT, Pover RCF, Bakx N, Lahti-Domenici JST, Bruinsma TJ, Warmoes MO, Bernards R, et al: Converting a breast cancer microarray signature into a high-throughput diagnostic test. BMC Genomics 2006, 7:278

20. Romond EH, Perez EA, Bryant J, Suman VJ, Geyer CE Jr, Davidson NE, Tan-Chiu E, Martino S, Paik S, Kaufman PA: Trastuzumab plus adjuvant chemotherapy for operable HER2-positive breast cancer. N Engl J Med 2005, 353:1673-1684

21. Piccart-Gebhart MJ, Procter M, Leyland-Jones B, Goldhirsch A, Untch M Smith I, Gianni L, Baselga J, Bell R, Jackisch C: Trastuzumab after adjuvant chemotherapy in HER2-positive breast cancer. N Engl J Med 2005, 353:1659-1672.

22. Muller YA, Chen Y, Christinger HW, Li B, Cunningham BC, Lowman HB, de Vos AM: VEGF and the Fab fragment of a humanized neutralizing antibody: crystal structure of the complex at $2.4 \mathrm{~A}$ resolution and mutational analysis of the interface. Structure 1998, 6:1153-1167.

23. Robinson CJ, Stringer SE: The splice variants of vascular endothelial growth factor (VEGF) and their receptors. J Cell Sci 2001, 114:853-865.

24. Bates DO, Cui T-G, Doughty JM, Winkler M, Sugiono M, Shields JD, Peat D, Gillatt D, Harper SJ: VEGF165b, an inhibitory splice variant of vascular endothelial growth factor, is down-regulated in renal cell carcinoma. Cancer Res 2002, 62:4123-4131.

25. Ladomery MR, Harper SJ, Bates DO: Alternative splicing in angiogenesis: the vascular endothelial growth factor paradigm. Cancer Lett 2007 249:133-142.

26. Merdzhanova G, Gout S, Keramidas M, Edmond V, Coll JL, Brambilla C, Brambilla E, Gazzeri S, Eymin B: The transcription factor E2F1 and the SR protein SC35 control the ratio of pro-angiogenic versus antiangiogenic isoforms of vascular endothelial growth factor-A to inhibit neovascularization in vivo. Oncogene 2010, 29:5392-5403.

27. Lin S, Coutinho-Mansfield G, Wang D, Pandit S, Fu X-D: The splicing factor $\mathrm{SC} 35$ has an active role in transcriptional elongation. Nat Struct Mol Biol 2008, 15:819-826.

28. Gout S, Brambilla E, Boudria A, Drissi R, Lantuejoul S, Gazzeri S, Eymin B: Abnormal expression of the pre-mRNA splicing regulators SRSF1, SRSF2, SRPK1 and SRPK2 in non small cell lung carcinoma. PLOS ONE 2012, 7:e46539.

29. Wang J, Manley JL: Overexpression of the SR proteins ASF/SF2 and SC35 influences alternative splicing in vivo in diverse ways. RNA 1995, 1:335-346.

30. Wang X, Cairns MJ: Gene set enrichment analysis of RNA-Seq data: integrating differential expression and splicing. BMC Bioinforma 2013, 14:S16.

31. Ma X, Zhang X: NURD: an implementation of a new method to estimate isoform expression from non-uniform RNA-seq data. BMC Bioinforma 2013, 14:220.

32. Rahman FA, Aziz N, Coverley D: Differential detection of alternatively spliced variants of Ciz1 in normal and cancer cells using a custom exon-junction microarray. BMC Cancer 2010, 10:482.

33. Bates DO, Harper SJ: Therapeutic potential of inhibitory VEGF splice variants. Future Oncol 2005, 1:467-473.

34. Harper SJ, Bates DO: VEGF-A splicing: the key to anti-angiogenic therapeutics? Nat Rev Cancer 2008, 8:880-887.

35. Nowak DG, Amin EM, Rennel ES, Hoareau-Aveilla C, Gammons M, Damodoran G, Hagiwara M, Harper SJ, Woolard J, Ladomery MR, Bates DO: 
Regulation of vascular endothelial growth factor (VEGF) splicing from pro-angiogenic to anti-angiogenic isoforms: a novel therapeutic strategy for angiogenesis. J Biol Chem 2010, 285:5532-5540.

36. Qiu Y, Hoareau-Aveilla C, Oltean S, Harper SJ, Bates DO: The antiangiogenic isoforms of VEGF in health and disease. Biochem Soc Trans 2009, 37:1207-1213.

37. Hilmi C, Guyot M, Pages G: VEGF spliced variants: possible role of antiangiogenesis therapy. J Nucleic Acids 2012, 2012:162692.

38. Guillaudeau A, Durand K, Bessette B, Chaunavel A, Pommepuy I, Projetti F, Robert S, Caire F, Rabinovitch-Chable H, Labrousse F: EGFR soluble isoforms and their transcripts are expressed in meningiomas. PLoS One 2012, 7:e37204.

39. Wang H, Zhou M, Shi B, Zhang Q, Jiang H, Sun Y, Liu J, Zhou K, Yao M, Gu J, et al: Identification of an exon 4-deletion variant of epidermal growth factor receptor with increased metastasis-promoting capacity. Neoplasia 2011, 13:461-471.

40. Imielinski M, Berger Alice H, Hammerman Peter S, Hernandez B, Pugh Trevor J, Hodis E, Cho J, Suh J, Capelletti M, Sivachenko A, et al: Mapping the hallmarks of lung adenocarcinoma with massively parallel sequencing. Cell 2012, 150:1107-1120

41. Varey AHR, Rennel ES, Qiu Y, Bevan HS, Perrin RM, Raffy S, Dixon AR, Paraskeva C, Zaccheo O, Hassan AB, et al: VEGF165b, an antiangiogenic VEGF-A isoform, binds and inhibits bevacizumab treatment in experimental colorectal carcinoma: balance of pro- and antiangiogenic VEGF-A isoforms has implications for therapy. Br J Cancer 2008, 98:1366-1379.

42. Lagarrigue M, Alexandrov T, Dieuset G, Perrin A, Lavigne R, Baulac S, Thiele H, Martin B, Pineau C: New analysis workflow for MALDI imaging mass spectrometry: application to the discovery and identification of potential markers of childhood absence epilepsy. J Proteome Res 2012, 11:5453-5463.

43. Solier S, Lansiaux A, Logette E, Wu J, Soret J, Tazi J, Bailly C, Desoche L, Solary E, Corcos L: Topoisomerase I and II inhibitors control caspase-2 Pre-Messenger RNA splicing in human cells. Mol Cancer Res 2004, 2:53-61.

44. Salon C, Eymin B, Micheau O, Chaperot L, Plumas J, Brambilla C, Brambilla E, Gazzeri S: E2F1 induces apoptosis and sensitizes human lung adenocarcinoma cells to death-receptor-mediated apoptosis through specific downregulation of c-FLIPshort. Cell Death Differ 2006, 13:260-272.

45. Salon C, Merdzhanova G, Brambilla C, Brambilla E, Gazzeri S, Eymin B: E2F1, Skp2 and cyclin E oncoproteins are upregulated and directly correlated in high-grade neuroendocrine lung tumors. Oncogene 2007, 26:6927-6936.

46. Gandoura S, Weiss E, Rautou P-E, Fasseu M, Gustot T, Lemoine F, Hurtado-Nedelec M, Hego C, Vadrot N, Elkrief L: Gene-and exon-expression profiling reveals an extensive LPS-induced response in immune cells in patients with cirrhosis. J Hepatol 2013, 58:936-948.

47. Wang E, Aslanzadeh V, Papa F, Zhu H, de la Grange P, Cambi F: Global profiling of alternative splicing events and gene expression regulated by hnRNPH/F. PLOS ONE 2012, 7:e51266.

48. Livak KJ, Schmittgen TD: Analysis of relative gene expression data using real-time quantitative PCR and the $2-\Delta \Delta C T$ method. Methods 2001, 25:402-408

doi:10.1186/1476-4598-13-9

Cite this article as: Pesson et al:: A dedicated microarray for in-depth analysis of pre-mRNA splicing events: application to the study of genes involved in the response to targeted anticancer therapies. Molecular Cancer 2014 13:9.

\section{Submit your next manuscript to BioMed Central and take full advantage of:}

- Convenient online submission

- Thorough peer review

- No space constraints or color figure charges

- Immediate publication on acceptance

- Inclusion in PubMed, CAS, Scopus and Google Scholar

- Research which is freely available for redistribution 